\title{
Erratum to: Fabrication of a Functional Relief on the Surface of a Polyvinyl Chloride Film by Nanosecond Laser Microtexturing
}

\author{
I. V. Krylach ${ }^{a, *}$, S. I. Kudryashov ${ }^{a, b}$, R. O. Olekhnovich ${ }^{a}$, M. I. Fokina ${ }^{a}$, V. E. Sitnikova ${ }^{a}$, \\ M. K. Moskvina ${ }^{a}$, N. N. Shchedrina ${ }^{a}$, and M. V. Uspenskaya ${ }^{a}$ \\ ${ }^{a}$ ITMO University, St. Petersburg, 171409 Russia \\ ${ }^{b}$ Lebedev Physical Institute, Moscow, 119991 Russia \\ *e-mail: irina-krylach93@mail.ru \\ Received March 23, 2021; revised March 23, 2021; accepted March 23, 2021
}

DOI: $10.1134 / \mathrm{S} 0030400 \mathrm{X} 21040287$

Figure 6 should read as follows:

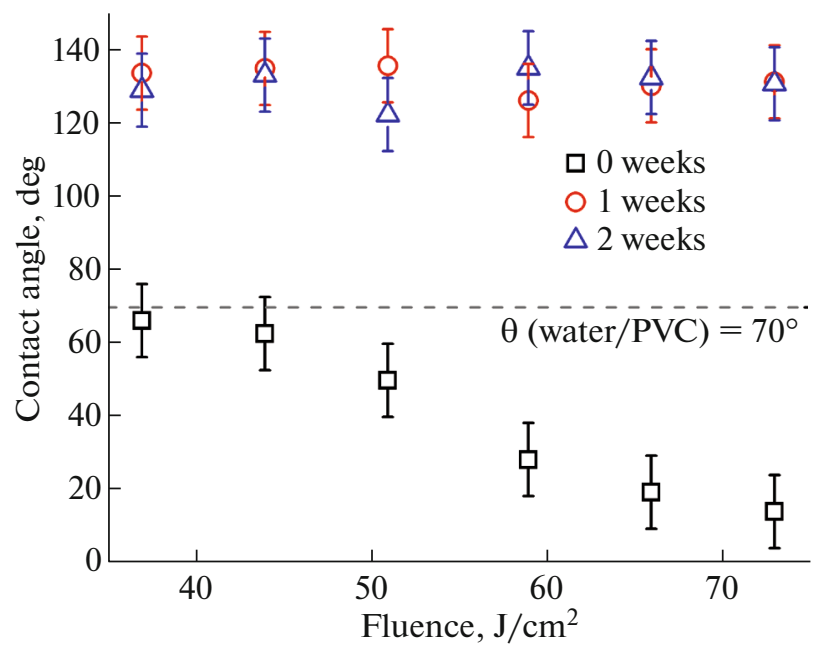

Fig. 6.

The original article can be found online at https://doi.org/10.1134/S0030400X20080184 